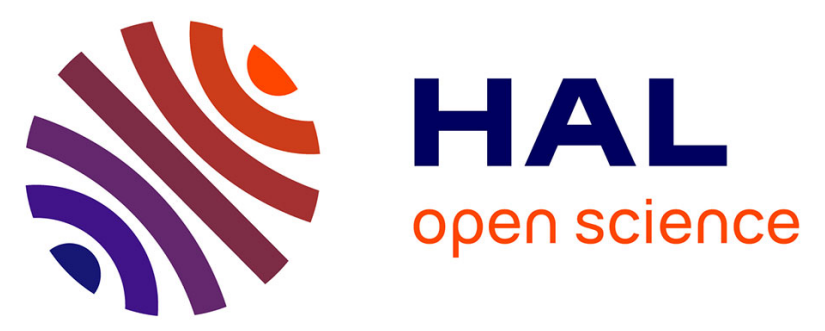

\title{
TRANSPORT PROPERTIES, GIANT MOMENTS AND NEARLY MAGNETIC IMPURITIES IN SOME NICKEL ALLOYS NEAR THE MAGNETIC TRANSITION
}

\author{
A. Amamou, F. Gautier, B. Loegel
}

\section{To cite this version:}

A. Amamou, F. Gautier, B. Loegel. TRANSPORT PROPERTIES, GIANT MOMENTS AND NEARLY MAGNETIC IMPURITIES IN SOME NICKEL ALLOYS NEAR THE MAGNETIC TRANSITION. Journal de Physique Colloques, 1974, 35 (C4), pp.C4-217-C4-222. 10.1051/jphyscol:1974439 . jpa-00215630

\section{HAL Id: jpa-00215630 https://hal.science/jpa-00215630}

Submitted on 1 Jan 1974

HAL is a multi-disciplinary open access archive for the deposit and dissemination of scientific research documents, whether they are published or not. The documents may come from teaching and research institutions in France or abroad, or from public or private research centers.
L'archive ouverte pluridisciplinaire HAL, est destinée au dépôt et à la diffusion de documents scientifiques de niveau recherche, publiés ou non, émanant des établissements d'enseignement et de recherche français ou étrangers, des laboratoires publics ou privés. 


\title{
TRANSPORT PROPERTIES, GIANT MOMENTS AND NEARLY MAGNETIC IMPURITIES IN SOME NICKEL ALLOYS NEAR THE MAGNETIC TRANSITION
}

\author{
A. AMAMOU (*), F. GAUTIER and B. LOEGEL (*) \\ Laboratoire de Structure Electronique des Solides (**), Université Louis-Pasteur, \\ 4, rue Blaise-Pascal, 67000 Strasbourg, France
}

\begin{abstract}
Résumé. - L'étude systématique d'une série d'alliages concentrés à base de nickel du type $\mathrm{Ni}_{1-c} \mathrm{~T}_{c}(\mathrm{~T}=\mathrm{V}, \mathrm{Mo}, \mathrm{Cr}, \mathrm{Ru}, \mathrm{Ir})$ a mis en évidence des propriétés de transport ainsi que des propriétés magnétiques particulières au voisinage de la transition de l'état paramagnétique vers l'état ferromagnétique. Des mesures d'aimantation ont été effectuées dans des champs magnétiques allant de 0 à $52 \mathrm{kOe}$ et pour un domaine de température compris entre $1,7 \mathrm{~K}$ et $300 \mathrm{~K}$. Les résultats obtenus et leur analyse permettent d'attribuer la très forte contribution à la résistivité, aux alentours de la transition magnétique, à l'existence d'impuretés presque magnétiques et magnétiques (nuages). De plus, les mesures de magnétorésistance mettent en évidence le blocage - par un champ magnétique - des processus de diffusion par renversement de spins dus à ces impuretés.
\end{abstract}

Abstract. - Magnetic measurements as well as electrical resistivity and magnetoresistance measurements for temperatures ranging between $1.2 \mathrm{~K}$ and $300 \mathrm{~K}$ show that the transition from the para- to the ferromagnetic state, for nickel based concentrated alloys, occurs in a rather inhomogeneous way. The magnetic and transport properties show evidence for the existence of giant moments and nearly magnetic impurities whose concentrations increase with increasing nickel content.

The inhomogeneous nature of the transition from the paramagnetic to the ferromagnetic state in nickel based alloys was first pointed out in $\mathrm{NiCu}$ [1] and $\mathrm{NiRh}$ [2] alloys. Magnetization data on these alloys showed qualitatively that the ferromagnetic state occurs from the coupling of giant moments whose concentration increases with increasing nickel content. The systematic study that we have done on several nickel solid solutions $\mathrm{Ni}_{1-c} \mathrm{~T}_{c}(\mathrm{~T}=\mathrm{V}, \mathrm{Mo}, \mathrm{Cr}, \mathrm{Ru}, \mathrm{Ir})$ shows that the inhomogeneous nature of the transition and the existence of giant moments are general characteristics of the magnetic transition from paramagnetic to ferromagnetic state.

In a first section we summarize briefly the magnetization measurements in nickel alloys, especially for $\mathrm{Ni}_{1-c} \mathrm{~V}_{c}$ and $\mathrm{Ni}_{1-c} \mathrm{Mo}_{c}$ alloys. As a first approximation the results are analyzed in a model where the magnetization arises from a band polarization term and from a single type of magnetic moments whose concentration increases rapidly with nickel concentration [3]. However a more detailed study shows that a better interpretation of our results can be given by assuming that the magnetization originates from several types of magnetic moments corresponding to various local environments $[4,5,6]$.

In the second section we summarize the results for the temperature dependence of the resistivity

(*) Part of a thesis to be presented at the Université LouisPasteur of Strasbourg, France.

(**) Equipe de recherche associée au C. N. R. S. $n^{\circ} 100$.
$(4 \mathrm{~K}<T<300 \mathrm{~K})$; this variation [3, 7] and the corresponding magnetoresistance behaviour [8] are related to the occurrence of the magnetic moments.

1. The magnetic properties of concentrated nickel based alloys. - The simplest analysis of the magnetization is given by assuming [1] a single type of magnetic impurities leading to a Curie-Weiss law (Fig. 1) and a non-magnetic part leading to a nearly temperature independent susceptibility $\chi^{\prime}$. The total magnetization is then given by:

$$
M(H, T)=\chi^{\prime} H+\frac{C_{\mathrm{cw}} H}{T-\theta} .
$$

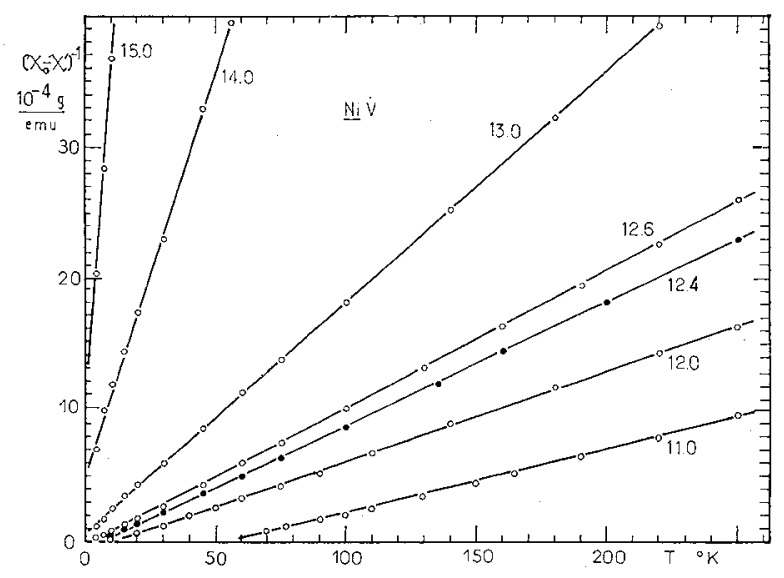

FIG. 1. - Variation of the initial susceptibility versus temperature in NiV alloys. 
TABLE I

\begin{tabular}{|c|c|}
\hline$c$ at. $\% \mathrm{~V}$ & $\begin{array}{c}\chi^{\prime} \\
\mathrm{emu} / \mathrm{g}\end{array}$ \\
\hline - & - \\
\hline 15 & $4.8 \times 10^{-6}$ \\
\hline 14 & 5.2 \\
\hline 13 & 5.2 \\
\hline 12.6 & 5.0 \\
\hline 12.4 & 5.0 \\
\hline
\end{tabular}

The magnetic moment $\mu^{*}$ of the magnetic impurity and its concentration $c^{*}$ are obtained from (1) where $C_{\mathrm{cw}}=c^{*} \mu^{* 2} / 3 k_{\mathrm{B}}\left(k_{\mathrm{B}}:\right.$ Boltzmann's constant) and from the saturation magnetization $\sigma_{0}=c^{*} \mu^{*}$.

In the low temperature and high field limits the magnetization can be expressed according to the following relation :

$$
M(H, T)=\chi_{H} H+M_{0}(T)
$$

and table I gives the values of $\chi^{\prime}, \theta, c^{*}$, and $\chi_{H}$ in the case of nickel vanadium alloys.

The values of the giant moments $\mu^{*}$ are strongly dependent on the non magnetic element $T$. They increase with decreasing critical concentration $c_{\text {crit }}$ for ferromagnetism, and this can be easily explained in the local environment model [4] : for NiCu alloys $\left(c_{\text {crit }}=56\right.$ at. $\left.\% \mathrm{Cu}\right)$ the concentration dependence of the saturation magnetization is consistent with a model for which a nickel atom carries a moment when it is surrounded by - at least - eight or nine nearest neighbours [5] giving an average cluster moment of about $10 \mu_{\mathrm{B}}$.

When $c_{\text {crit }}$ decreases, there is an increasing probability for a given nickel atom to be surrounded by other nickel atoms : this explains qualitatively why the moment per cloud $\mu^{*}$ is higher in NiRh alloys $\left(\mu^{*}=25 \mu_{\mathrm{B}}, c_{\mathrm{crit}}=37\right.$ at. $\left.\% \mathrm{Rh}\right)$ [2] and still higher in NiV alloys $\left(\mu^{*}=40 \mu_{\mathrm{B}}, c_{\text {crit }}=12.8\right.$ at. $\%$ V) [3] (Table II).

\section{TABLE II}

Values of the giant magnetic moments for nickel alloys $\mathrm{Ni}_{1-c} \mathrm{~T}_{c}$

\begin{tabular}{rcccc} 
T & $\mathrm{Cu}$ & $\mathrm{Rh}$ & \multicolumn{1}{c}{ V } & Mo \\
$\mu^{*}\left(\mu_{\mathrm{B}} /\right.$ cloud $)$ & $\overline{10}$ & $\overline{25}$ & $\overline{40}$ & $\overline{30}$ \\
$c_{\text {crit }}($ at. $\% \mathrm{~T})$ & 56 & 37 & 12.8 & 10.8
\end{tabular}

However, two remarks are to be made concerning the preceding analysis :

(i) for alloys with very low values of $c_{\mathrm{crit}}(\mathrm{NiV}$, $\mathrm{NiMo}, \mathrm{NiCr}$ ), the probability for a nickel atom to have twelve nickel nearest neighbours is very large and the concentration dependence of the saturation magnetization cannot be described by a simple model taking only into account the first neighbours ;

(ii) the high field $\chi_{H}$ (cf. (2)) and low field $\chi^{\prime}$ susceptibilities have to be identical if the above analysis would be fully consistent; in fact we obtain increasing non-zero values for $\chi_{H}-\chi^{\prime}$ as the critical composition is approached. This difficulty is observed for all the nickel alloys (cf. [1]) and is a general feature for results obtained near the critical composition. Furthermore, for a given specimen, the magnetization $M-\chi^{\prime} H$ is not a function of $H / T$ and the saturation is less easy than expected for a Brillouin (or Langevin) function; for a given temperature, the saturation becomes relatively much easier when the nickel concentration increases (Fig. 2).

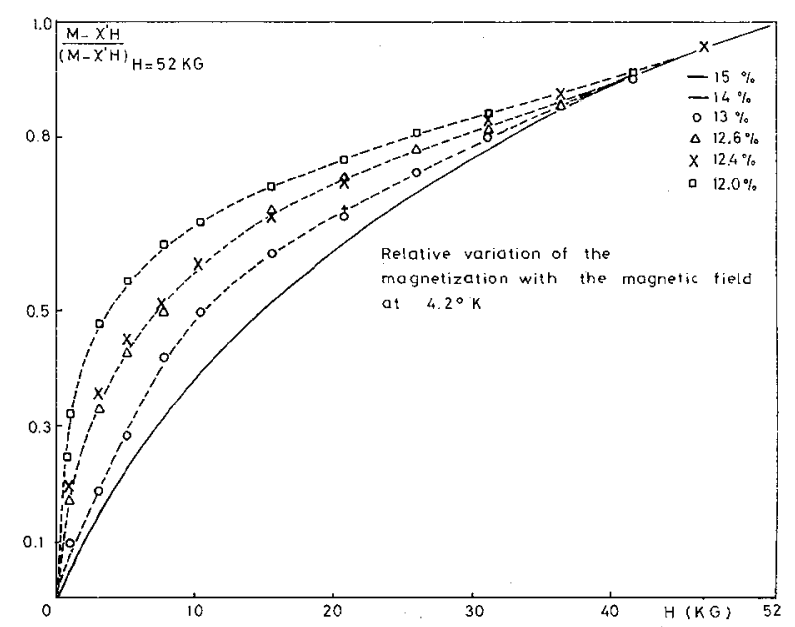

FIG. 2, - Relative magnetization curves $M(H) / M(52 \mathrm{kOe})$ at $T=4.2 \mathrm{~K}$ for several nickel vanadium alloys.

From these last remarks, we suggest thus that the magnetization arises from several magnetic moments whose magnitude increases when the nickel concentration increases : the magnetization curves $M(H, T)$ can be represented for $4 \mathrm{~K}<T<300 \mathrm{~K}$ as resulting from three terms which are unambiguously determined $\left({ }^{1}\right):(a)$ a temperature independent term $\chi^{\prime} H$

(1) Another separation method is proposed by Mishra and Beck (1973, to be published) for $\mathrm{Ni}_{0.4} \mathrm{Cu}_{0.6}$ by using a least squares fit analysis of the magnetization data to several Brillouin or Langevin functions. 


\section{TABLE III}

Nearly magnetic and magnetic impurities in nickel vanadium alloys

\begin{tabular}{|c|c|c|c|c|c|c|c|}
\hline $\begin{array}{ll} & c \\
\text { at. } \% \mathrm{~V}\end{array}$ & $\begin{array}{c}\chi^{\prime}+\chi^{\prime \prime} \\
(4.2 \mathrm{~K}) \\
\mathrm{emu} / \mathrm{g}\end{array}$ & $\begin{array}{c}C^{\prime \prime} \\
\text { emu Kg }\end{array}$ & $\begin{array}{l}\theta^{\prime \prime} \\
\mathrm{K}\end{array}$ & $\begin{array}{c}c_{1} \\
\left(\mu_{1}=7 \mu_{p}\right)\end{array}$ & $\begin{array}{c}c_{2} \\
\left(\mu_{2}=40 \quad u_{0}\right)\end{array}$ & $\begin{array}{c}c_{3} \\
\left(\mu_{3}=145 \mu_{\mathrm{P}}\right)\end{array}$ & \\
\hline $\begin{array}{l}\text { at. } \% \mathrm{~V} \\
15\end{array}$ & $\begin{array}{c}\mathrm{emu} / \mathrm{g} \\
5.4\end{array}$ & $\begin{array}{c}\text { emu Kg } \\
116 \times 10^{-6}\end{array}$ & $\begin{array}{l}\mathrm{K} \\
+40\end{array}$ & $\begin{array}{r}\left(\mu_{1}=7 \mu_{B}\right) \\
12 \times 10^{-5}\end{array}$ & $\begin{array}{c}\left(\mu_{2}=\begin{array}{c}40 \\
0\end{array} \mu_{\mathbf{B}}\right) \\
0\end{array}$ & $\left(\mu_{3}={ }_{0}^{145} \mu_{\mathrm{B}}\right)$ & $\begin{array}{c}\mathrm{emu} / \mathrm{g} \\
4.3 \times 10^{-6}\end{array}$ \\
\hline 14 & 7.0 & 315 & +40 & 31 & 0 & 0 & 4.3 \\
\hline 13 & 13.3 & 500 & +40 & 54 & $8.1 \times 10^{-5}$ & 0 & 4.3 \\
\hline 12.6 & 15.4 & _. & $\ldots$ & 71 & 14.5 & $1.2 \times 10^{-5}$ & - \\
\hline 12.4 & 19.6 & 一 & $\ldots$ & 90 & 18.0 & 1.9 & - \\
\hline
\end{tabular}

which represents the susceptibility of non magnetic atoms and is of the same order of magnitude as previously determined (Table II) $(b)$ a temperature dependent magnetization $\chi^{\prime \prime}(T) H$, proportional to the magnetic field which represents the susceptibility of nearly magnetic atoms, varying for high temperatures $(T>100 \mathrm{~K})$ as :

$$
\chi^{\prime \prime}(T)+\frac{C^{\prime \prime}}{T+\theta^{\prime \prime}}
$$

(c) a function of $H / T, M_{\text {mag }}(H / T)$ which results from the contributions of the magnetic moments whose Kondo and ordering temperatures are much lower than $4 \mathrm{~K}$. The total magnetization at temperature $T$ and for a magnetic field $H$ is given by :

$$
M(H, T)=\chi^{\prime} H+\chi^{\prime \prime}(T) H+M_{\mathrm{mag}}(H / T)
$$

$M_{\text {mag }}(H / T)$ corresponds to magnetic moments whose magnitudes increase when $c \rightarrow c_{\text {crit }}$. In order to represent qualitatively the variation of the saturation approach with concentration it can be separated into its various components by assuming that each of them follows a Brillouin function. Our results are summarized in table III. They show that the magnetization process occur from several types of magnetic moments $\mu_{1}, \mu_{2}, \ldots$ whose corresponding concentration $c_{1}, c_{2}, \ldots$ increase as the critical concentration is approached. For $c \cong c_{\text {crit }}$ (about 12.8 at. $\% \mathrm{~V}$ in $\mathrm{NiV}$ alloys) the magnetization saturates for much lower fields so that $M_{\text {mag }}(H / T)$ results from $\mu_{1}, \mu_{2}$ and from much higher magnetic moments whose magnitude is roughly estimated to be $\mu_{3}=150 \mu_{\mathrm{B}}$. Moreover, it appears that far from the critical concentration, the single magnetic moment ( $\mathrm{NiV}: \mu_{1}=7 \mu_{\mathrm{B}}$ ) is much smaller than the giant moments previously determined because a large part of the Curie-Weiss constant $C_{\mathrm{cw}}$ previously attributed to magnetic impurities is now corresponding to nearly magnetic impurities (Fig. 3). Finally $\theta^{\prime \prime}$ is roughly concentration independent $\left(\theta^{\prime \prime}=40 \mathrm{~K}\right.$ for NiV alloys, and $\theta^{\prime \prime}=70 \mathrm{~K}$ for NiMo alloys).

In conclusion, the present analysis in NiV and NiMo alloys shows that the magnetization originates from non magnetic, nearly magnetic and magnetic impurities whose concentrations increase with nickel

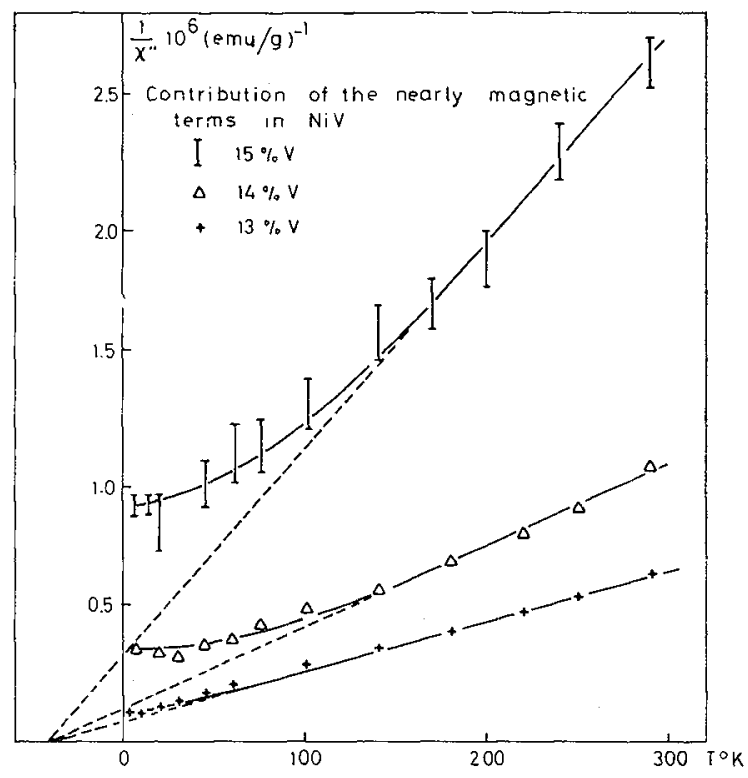

FrG. 3. - Variation of the susceptibility for nearly magnetic impurities in nickel vanadium alloys.

concentration. The giant moments defined by (1) [1] represent qualitatively the order of magnitude of the magnetization process, but they result from equations (i) which neglect the nearly magnetic term and (ii) which average incorrectly the various moment contributions to the Curie constant. Moreover, the alloys presenting strong increases of the temperature dependent part of the resistivity for $c \cong c_{\mathrm{crit}}$ (cf. section II) are probably characterized by the important nearly magnetic term we determined for $\mathrm{NiV}$ and NiMo alloys. This term is essential for the study of the transport properties when the temperature is much larger than the characteristic temperatures of the magnetic impurities.

2. Transport properties and giant moments in nickel alloys. - The temperature dependent part of the electrical resistivity shows a characteristic behaviour whose main points are summarized and discussed in this section in connection with the existence of nearly magnetic impurities.

If $\rho(0)$ represents the extrapolated residual resistivity 
at $T=0 \mathrm{~K}$ and $\rho(T)$ the total resistivity at temperature $T$, the general trends of the temperature dependent part of the resistivity $\rho(T)-\rho(0)$ are qualitatively represented by the phenomenological law $\rho(T)-\rho(0)=A T^{n}$ with $1<n \approx 2$ from $4.2 \mathrm{~K}$ up to about $100 \mathrm{~K}$ (Fig. 4). At much lower temperatures and for $c \cong c_{\text {crit }}$, a new behaviour appears ; the results for some preliminary resistivity measurements on $\mathrm{NiV}$ alloys are discussed elsewhere [9].

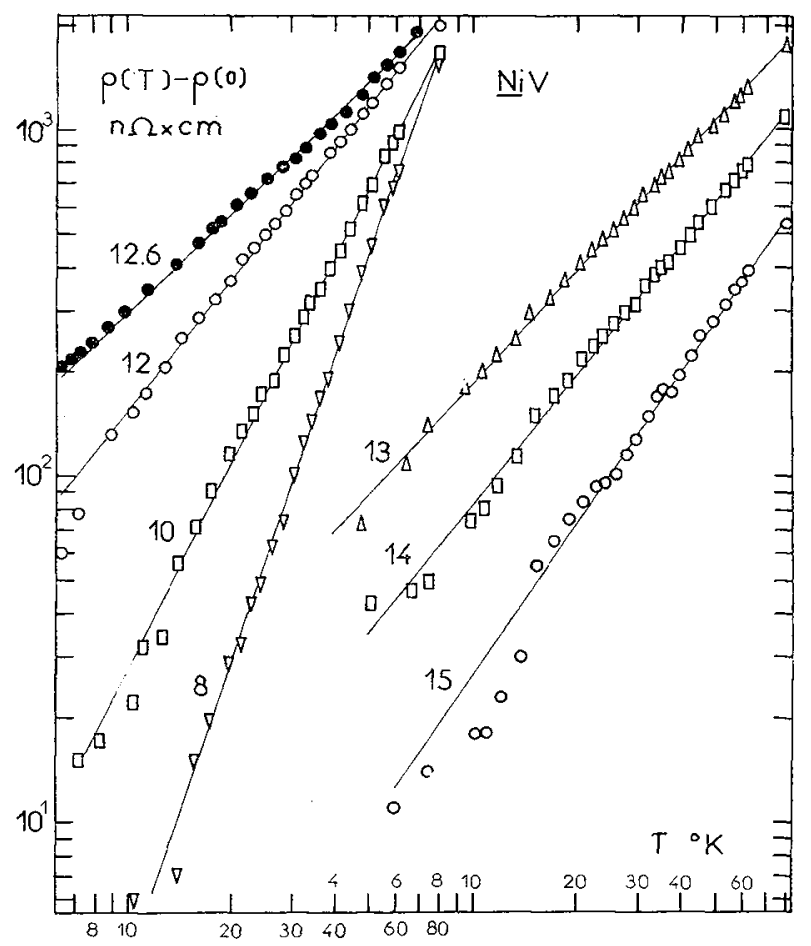

FIG. 4. - Temperature dependent part of the resistivity for nickel vanadium alloys. (The number on each curve gives the at. $\%$ vanadium concentration). The straight lines correspond to the phenomenological analysis $\rho(T)-\rho(0)=A T^{n}$.

An alternative phenomenological analysis can be given, although in a more restricted temperature range $(4<T \approx 60 \mathrm{~K}$ ) by representing the temperature dependent part as resulting from the sum of a linear and a quadratic term :

$$
\rho(T)-\rho(0)=B T+C T^{2} .
$$

For larger temperatures $(T>200 \mathrm{~K}), \rho(T)-\rho(0)$ increases linearly with temperature.

In both phenomenological analysis, the linear $(B T)$ or nearly linear $\left(A T^{n}\right)$ terms present strong maximums in the critical range of composition whereas the quadratic term $\left(C T^{2}\right)$ presents a slight maximum for $c<c_{\text {crit. }}$ At the critical composition, the coefficient $A$ (or $B$ ) is the largest for the lowest critical concentration. The results for $\mathrm{NiRh}$ alloys deduced from [10] and for NiPd alloys [11] are consistent with this picture (Fig. 5).

Furthermore, in NiV and NiMo alloys, where the

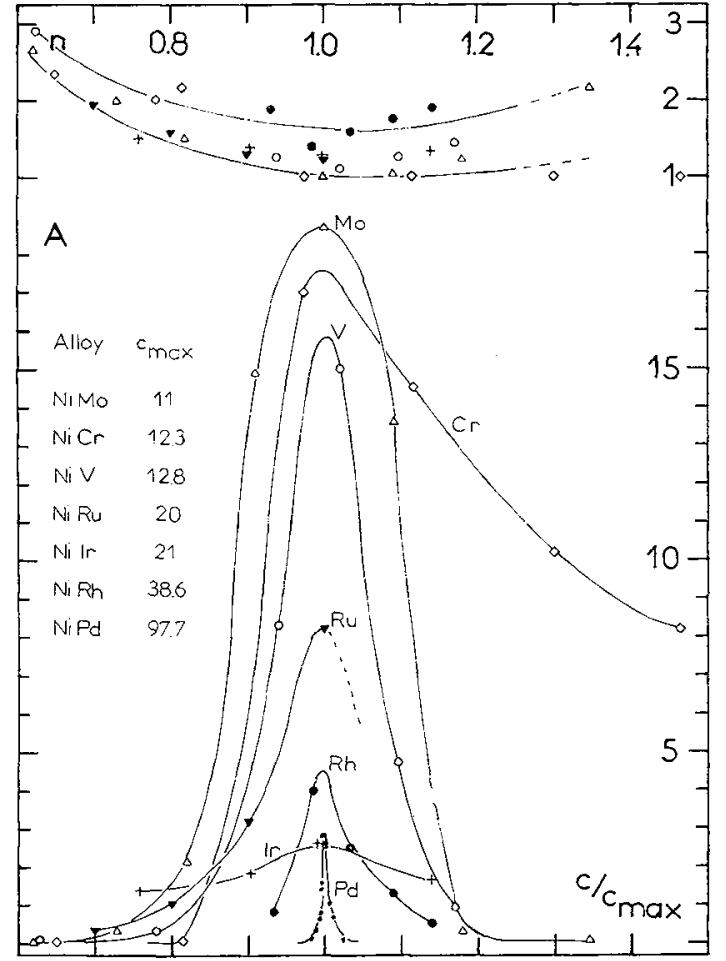

FIG. 5. - Variation of the coefficient $A$ (in $\mathrm{n} \Omega \mathrm{cm} \mathrm{K}^{-n}$ ) and of the $T$ power $n$ versus a reduced concentration $c / c_{\max }$, where $c_{\max }$ corresponds to the maximal value for $A$.

magnetic properties are well known (cf. section 1) it appears that $A$ (or $B$ ) for paramagnetic alloys $\left(c>c_{\mathrm{crit}}\right)$ is proportional to the saturation magnetization at low temperatures $\sigma_{0}$ or to the concentration of giant moments $c^{*}$, and also roughly proportional to the susceptibility of nearly magnetic impurities $\chi^{\prime \prime}$ at high temperatures (i. e. as long as a Curie-Weiss law holds).

The phenomenological analysis $\rho(T)-\rho(0)=A T^{n}$ can represent the effect of a single type of nearly magnetic impurity, while the analysis leading to the sum of a linear $(B T)$ and a quadratic $\left(C T^{2}\right)$ term can account for the effects of two types of nearly magnetic impurities characterized by spin fluctuation temperatures $\theta_{1}^{\prime \prime}$ and $\theta_{2}^{\prime \prime}$ such that $\theta_{1}^{\prime \prime}<\theta_{2}^{\prime \prime}$ and where $\theta_{2}^{\prime \prime}$ is in the measured temperature range. However, a choice between both analysis is difficult to made in the actual state of the experiments; in order to characterize the range of transition between linear and quadratic behaviour of $\rho(T)-\rho(0)$, our results on NiV alloys were fitted with Kaiser and Doniach's universal curve [12] leading to characteristic temperatures $T_{\mathrm{s}}$ decreasing from about $90 \mathrm{~K}$ for 15 at. $\% \mathrm{~V}$ to $10 \mathrm{~K}$ for 13 at. $\% \mathrm{~V}$.

The magnetoresistance properties on $\mathrm{NiV}$ alloys are consistent with the other transport and magnetic properties. The magnetoresistance is positive at low temperature : the resistivity increases linearly with applied magnetic field $H(5<H<45 \mathrm{kOe})$ :

$$
\rho(H, 4.2 \mathrm{~K})=\xi H .
$$




\section{TABLE IV}

The coefficients $A, B$ and $C$ for the temperature dependent resistivity of nickel vanadium alloys

\begin{tabular}{|c|c|c|c|c|c|c|}
\hline$c$ & $A$ (ng & $\left.\mathrm{m} \mathrm{K}^{-n}\right)$ & $B(\mathrm{n} \Omega$ & $\left(\mathrm{K}^{-1}\right)$ & $C(\mathrm{n} \Omega$ & $\mathrm{m} \mathrm{K}^{-2}$ ) \\
\hline at. $\% \mathrm{~V}$ & $H=0 \mathrm{kOe}$ & $H=43.7 \mathrm{kOe}$ & $H=0 \mathrm{kOe}$ & $H=43.7 \mathrm{kOe}$ & $H=0 \mathrm{kOe}$ & $H=43.7 \mathrm{kOe}$ \\
\hline 15 & 0.65 & 0.089 & 1.8 & 0 & $14.4 \times 10^{-2}$ & $15.4 \times 10^{-2}$ \\
\hline 14 & 4.8 & 2.4 & 8.3 & 5.0 & 12.0 & 14.6 \\
\hline 13 & 20.6 & 12.0 & 23 & 13.6 & 12.0 & 17.6 \\
\hline 12.6 & $26.6-28.8$ & 0.865 & $25.9-29.3$ & 11.0 & 3.0 & 17.1 \\
\hline 12.4 & & & $24.6-26.4$ & 10.8 & 4.6 & 15.9 \\
\hline
\end{tabular}

Moreover, for $c>c_{\mathrm{crit}}$, $\xi$ increases with increasing nickel content and reaches the largest value in the vicinity of the critical concentration (Fig. 6).

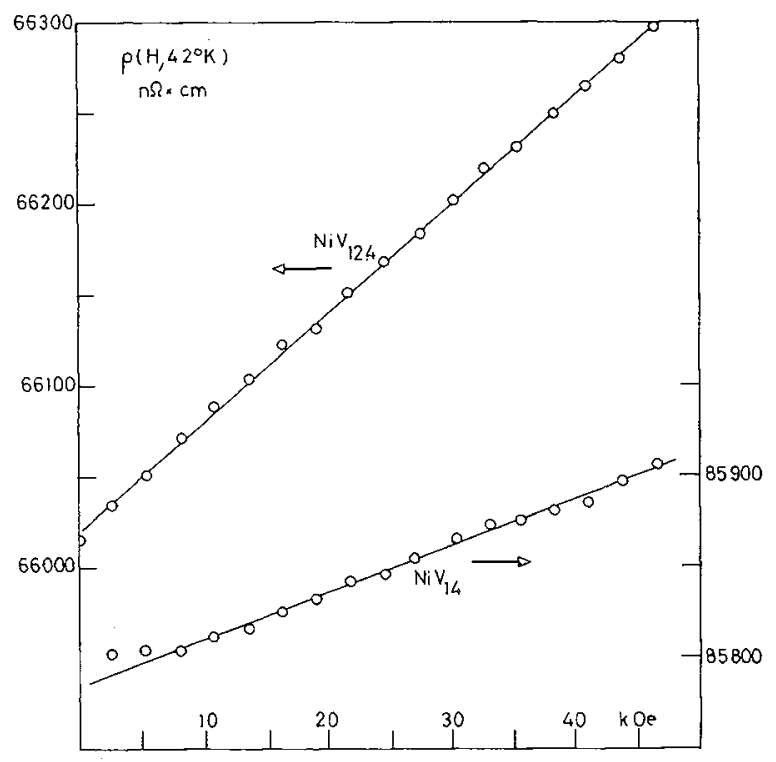

FIG. 6. - Typical field dependence of the electrical resistivity at $4.2 \mathrm{~K}$ for two nickel vanadium alloys.

The temperature dependent part of the resistivity decreases when a magnetic field is applied leading to a negative temperature dependent magnetoresistance (Fig. 7) and the phenomenological law $\rho(H, T)-\rho(H, 0)=A(H) T^{n(H)}$ can represent the experimental results: $A(H)$ decreases while $n(H)$ increases with magnetic field. In the range

$$
4<T \approx 60 \mathrm{~K}, \quad \rho(H, T)-\rho(H, 0)
$$

varies according to (5) with field dependent $B$ and $C$ terms : $B(H)$ decreases and $C(H)$ increases with magnetic field (Table IV).

The qualitative interpretation of these results is easily understood with the previous results on magnetic properties: the temperature dependent part of the resistivity is mainly related to the nearly magnetic impurities whose characteristic temperatures $\theta_{i}^{\prime \prime}$ are in the studied temperature range, and whose concentration increases as the critical concentration is

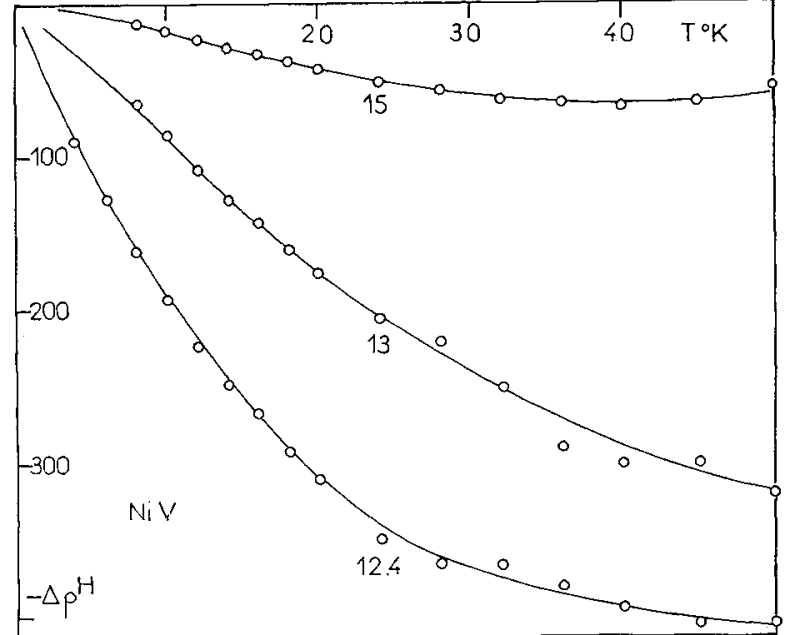

FIG. 7. - Magnetoresistance $\Delta p^{H}(T)$ in nickel vanadium alloys where $\Delta \rho^{H}(T)$ is defined by :

$$
\begin{gathered}
\Delta \rho^{H}(T)=(\rho(H, T)-\rho(H, 0))-(\rho(0, T)-\rho(0,0)) \\
\text { and for } H=43.7 \mathrm{kOe} .
\end{gathered}
$$

approached. The theories of localized spin fluctuation for isolated impurities $[13,14]$ accounts qualitatively for the temperature dependence of the resisitivity: $\rho(T)-\rho(0)$ varies as $T^{2}$ for $T \ll \theta^{\prime \prime}$, and as $T$ for $T\left\ulcorner\theta^{\prime \prime} ; \rho(T)-\rho(0)\right.$ saturates and can even present a maximum for larger temperatures $\left(T \gg \theta^{\prime \prime}\right)$.

At low temperatures, $A$ (or $B$ ) is roughly proportional to $\chi^{\prime \prime}$, suggesting that (5) represents in a phenomenological way the temperature dependence of the spin fluctuation resisitivity for a unique type of nearly magnetic impurity. The fact that $C$ presents a slight minimum for $c \cong c_{\text {crit }}$ and increases with magnetic field, while $B$ decreases, could be related to the fact that $\chi^{\prime \prime}$ represents only an average nearly magnetic term which results from several types of nearly magnetic impurities whose characteristic temperatures $\theta_{i}^{\prime \prime}$ are quite different and in (or below) the measured temperature range. The magnetoresistance for NiV alloys is consistent with the other experimental results : the negative temperature dependent magnetoresistance occurs from the quenching of the spin flip scattering of conduction electrons by the spin fluctuations leading to a decrease of the temperature dependent part of the resistivity with 
increasing magnetic field. The general features of the transport properties with or without applied magnetic field are very similar to those of nearly magnetic PdNi alloys $[14,15]$ which is a characteristic system where the nearly magnetic character is induced by nearly magnetic nickel impurities in a palladium host ; this shows qualitatively that the transport properties are dominated, in the studied temperature range, by the nearly magnetic impurities whose characteristics are given by our magnetic measurements.

\section{References}

11] Kouvel, J. S. and ComLy, J. B., Phys. Rev. Lett. 24 (1970) 598.

[2] Muellner, W. C. and Kouvel, J. S., A. I. P. Conf. Proc. No 5. Magnetism and Magnetic Materials, 1971. Ed. C. D. Graham and J. J. Rhyne (New York 1971) p. 487.

[3] Amamou, A. and Loegel, B., J. Phys. F (Metal Phys.) 3 (1973) L 79.

[4] Jaccarino, V. and Walker, L. R., Phys. Rev. Lett. 15 (1965) 258.

[5] Perrier, J., Tissier, B. and Tournier, R., Phys. Rev. Lett. 24 (1970) 313.

[6] Tholence, J. L. and Tourner, R., Phys. Rev. Lett. 25 (1970) 867.

[7] Gautier, F. and Loegel, B., Solid State Commun. 11 (1972) 1205.
[8] Amamou, A., Gautier, F. and Loegel, B., Int. Conf. on Magnetism, Moscow, 1973, Aug. 22-28.

[9] Laborde, O., Loegel, B. and Radhakrishna, P., 1973, J. Physique 35 (1974) C4-247.

[10] Houghton, R. W., Sarachik, M. P. and Kouvel, J. S., Solid State Commun. 10 (1972) 369.

[11] TaRi, A. and Coles, B. R., J. Phys. F (Metal Phys.), L 69 (1971).

[12] Karser, A. B. and Doniach, S., Int. J. Magnetism, 1 (1970) 11.

[13] Jullien, R., Beal, M. T. and Copblin, B., 1974, to be published in Phys. Rev. B.

[14] Purwins, H. G., Schulz, H. and Sierro, J., Int. J. Magnetism, 2 (1972) 153.

[15] Purwins, H. G., Talmor, Y., Sierro, J, and Hedgcock, F. T., Int. J. Magnetism, 3 (1972) 337. 